\title{
Parental rights and the importance of being parents
}

DOI:

10.1080/13698230.2016.1262316

\section{Document Version}

Accepted author manuscript

Link to publication record in Manchester Research Explorer

\section{Citation for published version (APA):}

Shields, L. (2016). Parental rights and the importance of being parents. Critical Review of International Social and Political Philosophy (CRISPP), 1-15. https://doi.org/10.1080/13698230.2016.1262316

\section{Published in:}

Critical Review of International Social and Political Philosophy (CRISPP)

\section{Citing this paper}

Please note that where the full-text provided on Manchester Research Explorer is the Author Accepted Manuscript or Proof version this may differ from the final Published version. If citing, it is advised that you check and use the publisher's definitive version.

\section{General rights}

Copyright and moral rights for the publications made accessible in the Research Explorer are retained by the authors and/or other copyright owners and it is a condition of accessing publications that users recognise and abide by the legal requirements associated with these rights.

\section{Takedown policy}

If you believe that this document breaches copyright please refer to the University of Manchester's Takedown Procedures [http://man.ac.uk/04Y6Bo] or contact uml.scholarlycommunications@manchester.ac.uk providing relevant details, so we can investigate your claim.

\section{OPEN ACCESS}




\title{
Parental rights and the importance of being parents ${ }^{1}$
}

\author{
Liam Shields \\ University of Manchester
}

A version of this paper was accepted for publication by the Critical Review of International Social and Political Philosophy

\begin{abstract}
It is widely accepted both that adequate parents cannot be denied custodial rights for the reason that someone else would do a better job and that children should be reared in adequate families, even when communal arrangements would be no worse for children and would promote equality. So-called dual interest theorists of parental rights defend their view on the grounds that it can fully explain these convictions because only their view attaches importance to the interests of the parents which are adversely affected. In this paper the author argues that this defence of the dual interest view is flawed because some of these convictions can be explained only at the expense of others. The author offers an alternative defence of the dual interest view, one that requires us to revise these widely accepted convictions but ultimately puts the dual interest view on a surer footing.
\end{abstract}

\footnotetext{
${ }^{1}$ I want to thank audiences at the Mc Coy Family Center for Ethics in Society Postdoc Workshop and at the Ethics of Child-Rearing workshop hosted by Stanford University in April 2014, as well as the audience at the MANCEPT seminar series, University of Manchester, January 2016. I am very grateful to Sarah Hannan, Colin Macleod, Rob Reich, Julie Rose Anca Gheaus, Stephanie Collins, Brian Carey, Jodie Lamb, Richard Child and Luara Ferracioli for detailed and helpful comments on previous drafts and related matters.
} 
Keywords: Upbringing, Parents' Rights, Family Values, Children

\section{Introduction}

In many contemporary societies parental rights protect parents from certain types of interference. Parental rights include the right to parent, which is held by adults, and the rights of parents, which are only held by parents. The right to parent protects its bearer from interference in their becoming and continuing to be parents. The rights of parents typically protect their bearers from interference in decisions about how the child lives, including what school they attend, where they live, and their involvement in religious practices. That the interests of their child, some other adult, or society as a whole would be better promoted under some alternative custodial arrangement is not usually taken to be a good reason to deny adequate parents the right to parent that child.

We could configure parental rights in other ways. We could admit that the prospect of a superior upbringing for the child is more often a good reason to re-allocate rights to parent particular children. We could admit that child-rearing should usually be left to institutions or collectives, like orphanages or the kibbutz. Whether we should make these changes, and which ones, depends on the interests that are relevant to the justification of these rights.

Two positions dominate the literature on the justification of parental rights. Child centered theorists focus exclusively on the interests of children and hold that schemes of rights are justified to the extent that they best serve those interests (see Brighouse, 1998, Arneson, 2000, Vallentyne, 2003, Hannan and Vernon, 2008, Dwyer, 2011). Dual interest theorists argue that parental interests, as well as the interests of children, are relevant to such justifications (see Schoeman, 1980, Clayton, 2006, Brighouse and Swift, 2014, Macleod, 2015). 
To defend the dual interest view one must explain why including a parental interest generates a more plausible account of parental rights than excluding it. The most common strategy for defending the dual interest view is to argue that it is only by including a parental interest that we can ground a scheme of parental rights that is consistent with certain widely held convictions. In this paper, I show why this strategy fails and instead put forward an alternative strategy. This alternative strategy requires us to revise some of our convictions but it ultimately places the dual interest view on a surer footing.

In Section One, I explain the commonly used strategy for defending a dual interest view and show that this strategy fails because the parental interest that is used to explain why children should be reared by families and not communally can be held by prospective parents as well as current parents and so cannot explain why current adequate parents should retain their rights when prospective parents would fare better in terms of the child's interests or equality. In Section Two, I show that there is no plausible way to amend this strategy to include a separate interest in parenting one's current or biological child. The reason for this is that to explain why children should be reared in families and not communally we need to grant the interest in parenting that is possessed by prospective as well as current parents a special status, but that special status is inconsistent with the privilege we must grant to current and biological parents to explain why they retain their rights when a prospective parent would fare better in terms of the child's interests or equality. I conclude that no dual interest view can fully explain the convictions that it was thought it could and so we must decide which of the convictions it is most important to explain. In Section Three, I argue that the dual interest view can, nevertheless, be defended and is in fact best defended by partially explaining each of the convictions rather than fully explaining some at the expense of others. In Section Four, I conclude with some remarks about the usefulness of this position. 


\section{The Common Strategy}

The following are convictions about the right to parent, each of which involves a conflict between the interests of parents, on the one hand, and the interests of children and wider society, on the other.

No Parents: the minimally decent family should be the favoured vehicle for child rearing, even when institutional or collective modes of child rearing would be best in terms of the child's interests or would enhance equality (Brighouse and Swift, 2006, p. 97 and 2014, p. 86, Macleod, 2015, p. 213).

Better Parents: It is impermissible to change child custody when current parents provide a minimally good upbringing, even if doing so would be best in terms of the child's interests (Brighouse and Swift, 2006, p. 86 and p. 106 and 2014, p. 95, Clayton, 2006, p. 58, Hannan and Vernon, 2008, p. 175, Gheaus 2012, p. 434).

Reshuffle: It would be wrong to reshuffle custody of babies at birth so that children are reared by those other than birth parents who are at least minimally good, even if doing so would be best in terms of the child's interests or would enhance equality (Gheaus, 2012, p. 434, Macleod, 2015, p. 213).

These convictions are held by many people and are respected by many legal systems. Several political theorists, and not only dual interest theorists, have noted the force of these convictions. 
Explaining these convictions, especially No Parents and either Reshuffle or Better Parents, is taken to be an important test of any account of parental rights and, in particular, is taken to be a key point in favour of the dual interest view.

These convictions cannot be explained by the child centered view since it is stipulated that children are either better off or no worse off. But in each case parents' interests are set back. For example, in Reshuffle, the biological parents' interest in rearing their biological child is set back; in Better Parents, the current parents' interest in continuing to rear their child is set back; in No Parents, the prospective parents' interest in rearing a child is set back. Because each conviction involves a parent's interest being adversely affected, the dual interest view seems to be a promising way of grounding a set of parental rights that is consistent with these convictions. But whether it can do so depends on the nature of the proposed parental interest.

To explain these convictions a dual interest view must endorse a parental interest that meets three conditions. First, the parental interest must be weighty enough to counter-veil the suprathreshold improvements in terms of the child's interests and any improvements in terms of equal opportunity (Brighouse and Swift, 2009, p. 50 and p. 52). Second, the parental interest must be special in some way that means that our interest in parenting cannot be readily substituted. If there were an abundance of good substitutes for the contribution that parenting makes to flourishing then prospective parents would not have a serious complaint about No Parents or Better Parents. Instead, we could offer those who are not given opportunities to parent other opportunities to pursue valuable projects that are adequate substitutes. For example, more fulfilling relationships with romantic partners, friends or even pets may be adequate substitutes for parenting (see Cooke, 2011, McTernan, 2015, p. 234, Liao, 2015, p. 162). Third, the parental interest must set up an asymmetry that tells in favour of the intuitive convictions. The requisite asymmetry can be 
explained for each conviction as follows. In No Parents, the parental interest must be adversely affected by institutional modes of child rearing but not adversely affected by familial modes of child rearing. In Reshuffle, the parental interest must be adversely affected by acts of reshuffling but not adversely affected by refraining from reshuffling. In Better Parents, the parental interest must be adversely affected by denying currently adequate parents' custody so that the child could be reared by parents who will maximize the child's expected wellbeing but the interest must not be adversely affected by allowing adequate parents to retain custody when a superior option for the child is available. I will now explain why the common strategy is flawed by discussion of the most influential dual interest view.

In several highly influential papers and, most recently, in their book, Family Values, Harry Brighouse and Adam Swift develop and defend an account of the value of the family that appeals to the familial relationship goods that are available through it. A key part of their dual interest account is the value of familial relationship goods to parents. They argue that the interest parents have in parenting makes a weighty and unique contribution to the flourishing of many adults (2014, p. 96) and grounds a serious claim against others (2014, p. 101). They state that the parent-child relationship is unique in virtue of possessing all of the following four features.

1) parties have unequal standing,

2) one party lacks the ability to exit,

3) the relationship elicits spontaneous and unconditional responses,

4) one party has a fiduciary role (2014, pp. 88-90).

They also say that, 
"The parent-child relationship is not, in our view, just another intimate relationship, valuable to both sides but substitutable for the adult by an additional relationship with a consenting adult. The relationship is, on the contrary, sui generis, a relationship that involves the adult in a unique combination of joys and challenges; experiencing and meeting these makes a distinctive set of demands on him, and produces a distinctive contribution to his well-being. Other intimate relationships have their own value, but they are not substitutes for a parenting relationship with a child."(2014, p. 88, see also Gheaus, 2012, and Weinstock and De Wispelaere, 2012 who make use of this characterization).

As described, the interest in familial relationship goods is of the right sort to explain No Parents. This is because the interest is weighty, non-substitutable and both unsatisfied in a regime of universal institutional child-rearing and satisfied in a regime where children are reared by parents (Gheaus, forthcoming).

Although Brighouse and Swift do not claim to have offered an explanation of why birth parents have rights to parent their children, and do not see this incompleteness as a weakness in their account, it is worth noting that the familial relationship goods account of the parental interest cannot explain Reshuffle because it has motivated others and has a certain intuitive force (Brighouse and Swift, 2006, p. 98 and fn. 4. Also see Brighouse and Swift, 2014, p. 104-110). The reason that Reshuffle cannot be explained by the interest in familial relationship goods is that it is an interest that a prospective or current parent may have with respect to a child. We have no reason to think that biological parents could only enjoy intimacy with that particular child, nor is there any reason to think that non-biological parents could not enjoy intimacy with children who are not 
biologically related to them. All four of the features stated above characterize many adoptive parent-child relations. The parental interest in familial relationship goods cannot explain Reshuffle because reshuffling not only involves sacrificing the current parent's interest but also involves satisfying the new parent's interest. For this reason, the interest in parenting, as described, tells in favour of reshuffling as well as against it. Reshuffle cannot be explained by the familial relationship goods account.

The same problem arises with respect to Better Parents, a conviction Brighouse and Swift would like to explain (2014, p. 95). Familial relationship goods are not only enjoyed by parents currently standing in those relationships but may also be enjoyed by prospective parents who would perform better in terms of the child's interests. While the parental interest plausibly defeats the child's interest in a maximally good upbringing, once their more basic interests are secured, the parental interest can be found on both sides of the trade off and will therefore cancel itself leaving only the child's best interests to be decisive in favour of being placed in the care of better parents. This implication is in direct opposition to the conviction expressed in Better Parents.

To summarise, the failure of this strategy stems from these dual interest theorists understanding Better Parents, No Parents and Reshuffle as a conflict between the interest of parents, on the one hand, and the non-basic interests of children and improvements in terms of equality on the other. While this an apt way to characterize the conflict in No Parents, which they can successfully explain, it is not an apt way to characterize Reshuffle and Better Parents, which they cannot successfully explain because a parental interest is involved on both sides of the conflict. Any interest in parenting that can be held by those adults who wish to become and would make good parents as well as those adults who are currently parenting will not be able to provide full explanation of Reshuffle and Better Parents. Other dual interest theorists endorse a parental 
interest of this sort and are equally unable to explain the convictions For example, Colin Macleod argues for a parental interest in creative self-extension and Matthew Clayton argues for a parental interest derived from our general interest in pursuing a conception of the good and in having the opportunity to found a family: to beget and raise children according to some appropriate standard (Macleod, 1997, p. 119 and p. 121, Clayton 2006, p. 54 and p. 60). Having shown that current dual interest views cannot explain these convictions, we must ask whether there are ways that we could amend this strategy so that a dual interest view could do so.

\section{Amending the Common Strategy}

The common strategy failed because the parental interest appealed to did not establish the asymmetry between current or biological parents and prospective parents that is required to explain Reshuffle and Better Parents. We could attempt to establish the requisite asymmetry by either replacing or supplementing the interest in parenting with specific interests in biological parenting or continuing to parent, which only current or biological parents can hold. I will now explain why each of these suggestions cannot save the strategy and will show that this reveals a deeper problem for dual interest theorists who wish to explain these convictions.

If we replace the general interest in the activity of parenting with a weighty, nonsubstitutable parental interest specifically in rearing one's own biological child or current child this seems to allow us to explain Better Parents and Reshuffle because this interest is not held by prospective parents, who would benefit from the proposed changes in parental rights. Moreover, so long as biological processes are required to create children, institutional childrearing entails severing a relationship grounded in genetic, gestational or proprietarian considerations and so, we might think, No Parents too could be explained in this way. 
There are two reasons why we should not amend the strategy in this way. First, the amended strategy would fail to explain many examples of No Parents, the conviction that is most widely shared. Even though institutional childrearing entails severing a relationship, an interest that only current and biological parents have in retaining custody of their child could not explain why children put up for adoption or those whose parents have died should be reared within a family rather than an communally or within an institutions, even though those options would be equally good in terms of the child's welfare. Without a weighty and non-substitutable general interest in the activity of parenting No Parents cannot be explained. But more decisively, we do have independent reason to endorse a general and weighty, though not necessarily non-substitutable, interest that prospective as well as current parents have in parenting a child. A failure to endorse such an interest would leave us unable to explain why prospective parents have a significant interest in parenting when they take steps to acquire parental rights. We would have no parentcentered reason to make the process of acquiring parental rights less arduous than it might be. Moreover, if it is valuable for biological or current parents to retain child-rearing rights it is most plausible to think that this is because parenting is a valuable activity to enter into and not only to continue to do. The general interest in the activity of parenting plausibly underpins more specific interests in parenting one's biological child or current child. We have independent reasons, then, to endorse a weighty parental interest that is capable of being held by prospective parents, whatever other biological or non-biological parental interests we might endorse. Since such an interest has to be non-substitutable to fully explain No Parents, the only strategy for someone wishing to explain No Parents and either Reshuffle or Better Parents is to try to supplement the general, weighty and non-substitutable interest in parenting with specific interests in rearing one's 
biological child or in continuing to rear one's child, but as we shall see, this reveals a major problem.

If we grant a claim that is made by Anca Gheaus in her paper "The Right to Keep One's Biological Baby", that the valuable relationship between parent and child forms during, and possibly prior to, gestation, then we have an argument for thinking that birth parents as well as current parents are already engaged in a valuable relationship with the child before Reshuffle and Better Parents could happen (2012, p. 453). For scepticism about this position see Brighouse and Swift, 2014, p. 108-109). If this is true, we might think that all we need in order to explain those convictions is a further argument for thinking that severing an existing relationship, at a cost to current and biological parents, is always significantly worse than being denied the opportunity to establish such a relationship in the first place, at a cost to prospective parents. In other words, we need an argument that vindicates what I call the Smokey Robinson Hypothesis since he sang "a taste of honey's worse than none at all" to express a similar sentiment.

There is some support for the hypothesis in the literature. Niko Kolodny argues that a shared history of encounters, such as a history of providing adequate care for your child, can justify duties of partiality. Although Kolodny is not discussing the right to parent, these reasons of partiality may tell against arrangements that would make it difficult or impossible for that partiality to find expression, such as rearing all children in the kibbutz, or more pertinently placing children into the custody of better parents rather than their current parents (2010, p. 68). Brighouse and Swift say that "it is worse to sever such a relationship than not to allow it to start. How bad it is to break the relationship - the cost of disruption - will of course depend on various considerations, such as how long it has been going on and the age of the child." (2014, p. 96). Although the cost of disruption appears to refer to a cost to the child it is plausible to think that could be also be 
worse for the parent. However, such considerations should be weighed up against the prospective parent's interest in a secure and resilient relationship and a future history of encounters as well as the additional child-centered and egalitarian reasons that are present in Reshuffle and Better Parents and it is not clear that they would fully explain those convictions. However, there is a more serious flaw in the strategy of explaining the convictions by appeal to parental interests, one that stems from the need for a non-substitutable general parental interest to explain No Parents.

If we accept a parental interest that is weighty, non-substitutable, and capable of being possessed by prospective as well as current parents, as it must be to fully explain No Parents, it becomes impossible to explain Reshuffle and Better Parents. A general and non-substitutable parental interest entails that opportunities to parent, and therefore satisfy that interest, should be distributed fairly and in accordance with their own principle. Because the interest is not reducible to a more fundamental interest, its importance to policy evaluation cannot be captured by another currency, such as a general welfarist principle. But explaining Reshuffle and Better Parents requires that we endorse a biological privilege whereby current (including birth) parents retain their rights of custody even where doing so has opportunity costs for the alternative prospective parent, as well as the child's supra-threshold well-being and equality of opportunity. Such a privilege renders opportunities to parent necessarily unequal due to factors outside of prospective parents' control and so it is plausible to believe that this is unfair. For example, under such a biological privilege, infertile individuals and those unable to find a willing or able reproductive partner will have no effective opportunity to parent when there is also a lack of incompetent reproductive parents and a lack of reproductive parents willing to put their children up for adoption. The biological privilege entailed by a specific parental interest conflicts with fair opportunities to parent, which is an implication of the general and non-substitutable parental interest. 
It could be argued that we can reconcile the biological privilege with equality of parental opportunity by giving everyone a negative right to parent. Since parenting starts prior to birth, as Gheaus' arguments suggest, biological and current parents have a negative rights that can explain Reshuffle and Better Parents. Two things are worth noting here. First, no one believes that the right to parent is unconditional and the conditions attached, at least for the dual interest theorist, are determined by a balancing of children's and parents' interests and possibly the value of equality too. This balance of reasons could ground conditions attached to such a right that would allow or recommend re-allocation in cases like Reshuffle and Better Parents. Second, the interest in parenting, which gave rise to the demand of equality of opportunity to advance that interest would not be respected by a negative right that never allowed re-allocation of rights except in extreme cases. The schemes of rights are justified by how well they respond to the relevant interests. A negative right to parent would treat some people with the non-substitutable interest in parenting, those who can produce biological children, very differently from others with that very same interest, those who cannot. It would not preserve equality of opportunity to fulfil their interest in parenting.

A second suggestion comes from Brighouse and Swift who say that "the right to parent is the right to enjoy a relationship that is somewhat resilient; it matters that the relationship with a child one is parenting be secure against circumstances that could be sufficient to defeat a claim to initiate such a relationship" (2014, p. 96). The interest itself, therefore, appears to ground a fairly resilient right that could be attributed equally to all parents and could explain why re-allocation is not usually permitted. Certainly parents have an interest in having a relatively secure right to parent, but this is held by all prospective as well as current parents and so it suggests that earlier intervention, like that involved in Reshuffle and possibly cases of Better Parents, is far better than 
later intervention. It does not follow from the interest in a resilient right that it is never or almost never permissible to make changes custodial arrangements.

The strategy of defending the dual interest view by its ability to explain No Parents and either Better Parents or Reshuffle fails because of a conflict between the underlying interests that are required explain them. Either we can explain No Parents, by invoking a weighty, nonsubstitutable interest in parenting, which generates a demand of equality of opportunity to parent and therefore fail to explain Reshuffle and Better Parents or we explain Reshuffle and Better Parents by invoking a weighty, non-substitutable interest in biological or current parenting and fail to explain No Parents. Now we must ask ourselves which of the convictions is most important to explain and whether that is enough to establish the superiority of the dual interest view to the child centered view.

\subsection{The Weak Dual Interest View}

No Parents, Better Parents and Reshuffle each have intuitive force and explaining those convictions remains an indicator of plausibility. But given that they cannot be explained by appeal to a parental interest, we must ask which convictions is it most important to explain and whether that would be enough to establish the superiority of the dual interest view to the child centered view.

In this section, I will argue that the most plausible position to take with respect to these convictions is to partially explain each of them rather than fully explain some of them at the expense of others. I argue that we should accept what I call the weak dual interest view. According to the weak dual interest view, the parental interest in parenting provides us with weighty, though not non-substitutable, reason to resist each of the convictions in some cases but none can be 
explained fully. I will now discuss each conviction and explain why the stance taken by the weak dual interest view is more plausible than the stance taken by other dual interest views and, importantly, the child centered view.

\section{Reshuffle and Better Parents}

The weak dual interest view can explain that, with respect to valuable relationships, birth or current parents and prospective parents are somewhat differently situated in contingent but important ways. Birth parents share genetic material with the child and tend to be better situated with respect to interacting with the child, especially the gestating mother. Some neuroscientific research suggests that facial resemblance effects the bonding process making it easier and more likely that genetic parents will successfully form the valuable parent-child bond (Bressen, 2009 and deBruine, 2004 and 2008). With respect to current parents, there are typically fewer obstacles in the way of the current parents maintaining a valuable relationship with the child than there are in the way of prospective parents. Since current parents are already in such a relationship or have begun forming one, there is relatively little risk of them not forming and maintaining the relationship and deriving the relevant goods from it, whereas there is usually some relatively higher risk, even if it is quite low in absolute terms, that the relationship will not form with other parents. Brighouse and Swift's discussion of the need for a secure and resilient relationship $(2014,96)$ and Kolodny's thought that a history of encounters makes a morally relevant difference (2010) could also provide some, though not a full, explanation of Reshuffle and Better Parents as was noted in the previous section. This cluster of contingent or defeasible factors generates a parent-centered presumption against re-allocation of parental rights from birth parents, which also applies to current parents. Because the interest is not non-substitutable, the complaint of unfairness in opportunities to parent lacks 
the force it has for those who pursued the common strategy. The weak dual interest view explains why we should be more resistant to these cases than the child centered view and dual interest views that would only explain No Parents since those views can never explain Reshuffle or Better Parents.

However, the presumption generated by the weak dual interest view does not imply that Reshuffle and Better Parents should always be resisted on parent-centered grounds, as dual interest theorists had hoped. But we should welcome this. If it was the case that reshuffling custody of babies at birth would severely diminish racism within a generation that would be a very strong reason in its favour and would be more powerful than the interest in rearing one's own biological child. Moreover, if the benefits to the child of being reared by people who are not birth or current parents are sufficiently large, even above the minimal threshold, we should be more open-minded about changes to custody (Shields, 2016). Future advances in our knowledge of children's development, health and education may mean that it is possible for children to live very much better lives than one meeting a minimal threshold and if there were large gains to be had from being reared by those other than your birth parents, a child denied this possibility would have a serious complaint. We should not assume that a child has few if any important interests beyond abuse and neglect. They have interests in their health, education, and in their capacities to form valuable relationships and these interests can be adversely affected in small ways as well as being affected in significant and very important ways. For this reason, we should not try to explain these two convictions in all cases, we should only try to explain the convictions sometimes.

\section{No Parents}


The weak dual interest view can explain that we should sometimes prefer the minimally decent family as the vehicle for child rearing, even when institutional or collective modes of child rearing would be best in terms of the child's interests or would enhance equality. This is because parenting is valuable for many adults, albeit not in a way that can provide a full explanation of No Parents. On the weak dual interest view the interest is, in principle, substitutable and need not be especially weighty. This, of course, means that we would have to accept that institutional or communal childrearing was justified in some cases, especially where the benefits are especially great for the child's welfare or equality. But I think that this is the most plausible position and we should welcome it. If, through technological development, robots become excellent and roughly equally excellent care givers as parents could aspire to be, then no parental child-rearing would be worth considering. If we could achieve far greater equality in upbringing through this method, then the interest many adults have in parenting may be successfully countervailed. To deny that the interest many adults have in parenting could be countervailed by any such gains for the child above a minimum threshold and for equality of opportunity is to give the interests of prospective parents the kind of priority that would block full explanation of the other two widely held convictions. With regard to No Parents, we should be open minded about the possible countervailing benefits outweighing the interest of parents. Other dual interest views that endorse a weighty, nonsubstitutable interest in the activity of parenting insist, implausibly, that we should never prefer institutional child rearing even when it would be better for the child or equality of opportunity.

The child centered view is, by contrast, never able to explain why we should prefer the at least minimally decent family when institutional or collective modes of child rearing would be best in terms of the child's interests or would enhance equality. Against the child centered view, we can point to the implausibility of always prioritizing the interests of the child, whatever they 
are. Like adults, children have some very important basic interests, but they also have less significant ones that are defeasible and when parents' significant interest in parenting will conflict with the child's less significant ones, the parents' interest can prevail, so we should not focus exclusively on the child's best interests (for a thought experiment intended to show why see Clayton, 2006, pp. 62-3). This intuition is strongest when thinking about allocating children for adoption. Adoption agencies may be able to offer more help, guidance and support so that the process is less difficult for prospective parents. On the child centered view we would have no parent-centered reason to favour these improvements, but it seems clear that there is some reason of this sort to help parents in these ways. Sometimes costs for the child are justifiable, when they are small and when the child's prospects are quite good anyway. Certainly where institutional child rearing is no better and no worse than parental child rearing, we should favour parental child rearing. But the child centered view problematically implies that we should be indifferent to institutional child rearing where the two are equally good. It thus overlooks the perhaps substitutable, but nevertheless weighty, contribution that parenting can make to one's life.

For these reasons, the weak dual interest view negotiates the considered convictions best. The child centered view fails to give any weight to the genuine interests of current, biological and prospective parents. Alternative dual interest views fail to give proper weight to the interests of the child and equality of opportunity. The weak dual interest view takes into account these interests and provides reasons for thinking that there are cases where No Parents, Reshuffle and Better Parents should trouble us and other cases where they should not.

\subsection{Conclusion}


Many people, including many political theorists, hold that parents should retain their rights in three important types of case. First, some believe that birth parents should retain the right to parent a child if they would do a minimally good job, even if the child would be better off elsewhere and even if reshuffling children at birth would make society more equal. Second, some believe that current parents should not be denied rights to rear their children simply because there is a better alternative, so long as they are doing a good job. Third, some believe that familial child-rearing should be preferred to institutional child rearing even where institutional child rearing is better for the child and better in terms of equality. Legal systems also seem to protect these dimensions of parental rights.

The most common strategy for defending the dual interest view is that it alone can explain these convictions and its rival, the child centered view, cannot. While dual interest theorists were apt to notice that the interests of children could sometimes be overridden by the interests of adults in parenting, they have overlooked the extent to which these convictions concern cases where there exists a conflict between the interests of current or biological parents, on the one hand, and prospective parents, on the other. This intra-parental conflict of interests meant that no dual interest view could hope to explain No Parents and either Reshuffle or Better Parents with amending their strategy. However, neither of the two ways of amending this strategy can succeed because in order to explain No Parents, the parental interest must be non-substitutable and weighty and this generates a requirement of equal opportunity to parent, but in order to explain Better Parents or Reshuffle, entails that opportunities to parent should be unequal. In light of this, dual interest theorists had to choose which of the convictions it was most important for them to explain. I defended a weak dual interest view that endorses a substitutable parental interest, which can provide some parent-centered resistance to re-allocation in the three cases and argued that it is 
more plausible than dual interest views that fully explain one conviction at the expense of others and the child centered view.

At this point one might ask 'What difference does it make?' It may appear that it makes little difference to custodial decisions to adopt the weak dual interest view. This is partly because the parental interest and the child's interests are well bound up. What is valuable for the child is in securing what they need to grow and develop and have loving and intimate relations. What is valuable for the parent is successfully providing what they need to grow and develop and to establishing a loving and intimate relation. Moreover, many people suspect, with good reason, that intimate relationships might be important for children to live a minimally good life and so nonfamilial child rearing settings may never be able to perform better with respect to the child's interests than parents can (Liao, 2015). This might lead us to believe that the difference between the weak dual interest view and child centered view is not so significant. There are two things we can say about this.

First, the inclusion of a weaker rather than strong parental interest is important when it comes to how we treat parents as a matter of public policy more generally. If we can make the activity of parenting or its pursuit easier and less burdensome then the weak dual interest view says that we have a strong but not non-substitutable reason to do so. Admitting a parental interest to our account of the interests relevant to child-rearing arrangements, as the dual interest view tells us, paves the way for this interest to be appealed to in arguments in favour of public financial support for child-rearing (see Casal and Williams, 1995, Clayton, 2006, pp. 61-86, Folbre, 1994, George, 1987, Olsaretti, 2013, Tomlin, 2015). Generally, we have parent-centred reasons to make parenting more satisfying and less difficult, even if it is not strong enough to outweigh the child's interests or equality of opportunity it may figure in other calculations. Whereas the child centered 
view says we lack any parent centred reason to do so and the strong parental interest would imply that we could only satisfy this interest in one way whereas the weak parental interest implies that we can satisfy it in other ways by taking a broader perspective on supporting policies that are good for relationships taken as a whole rather than specifically the parenting interest. But it also shows us that, even where the case for it seemed strongest, a non-substitutable interest in parenting, which could ground very strong claims to support for ART at the expense of other justice-salient values, like equality of opportunity, was not defensible.

Second, the fact that there is little practical difference between positions in our current world or that the counter-examples to child centered views are not likely to come to pass is not a defence of it as a fundamental normative principle. Such principles can be embarrassed by farfetched examples because it is often in those far-fetched examples that the convictions we use to evaluate such principles are clearest. Moreover, it is worthwhile knowing what the most plausible view is even if not a lot turns on that today. Often we don't fully appreciate the significance of what turns on it until we have grasped the distinction in theory.

\section{REFERENCES}

Arneson, R., 2000. Democracy is not intrinsically just. In: K. Dowding, R. Goodin, and C. Pateman, eds Justice and Democracy: Essays for Brian Barry. Cambridge, UK: Cambridge University Press, 40-58.

deBruine, L.M., 2004. Resemblance to self increases the appeal of child faces to both men and women. Evolution and Human Behaviour, 25 (3), 20, 142-154.

deBruine, L.M. et. al., 2008. Social perception of facial resemblance in humans. Archives of Sexual Behaviour 37 (1), 64-77.

Bressan, P. et. al., 2009. Men do not have a stronger preference than women for self-resemblant child faces, Archive of Sexual Behaviour. 38 (50), 657-664.

Brighouse, H., 1998. Civic education and liberal legitimacy. Ethics 108 (4), 719-745.

Brighouse, H. and Swift, A., 2006. Parents' rights and the value of the family. Ethics 117 (1), 80108.

Brighouse, H. and Swift, A. 2009. Legitimate parental partiality. Philosophy \& Public Affairs, 37 (1) $43-80$.

Brighouse, H. and Swift, A., 2014. Family Values. Princeton, NJ: Princeton University Press.

Casal, P. and Williams, A., 1995. Rights, equality and procreation. Analyse and Kritik, 17 (1), 93116 
Clayton, M., 2006. Justice and Legitimacy in Upbringing. New York: Oxford University Press, 2006.

Cooke, S., 2011. Duties to companion animals. Res Publica 17 (3), 261-274.

De Wispelaere, J., and Weinstock, D., 2012. Licensing parents to protect our children? Ethics and Social Welfare 6 (2), 195-205

Dwyer, J.G., 2011. The Relationship Rights of Children. New York: Cambridge University Press. Fogg-Davis, H., 2005. Racial randomization: imagining non-discrimination in adoption, In: Haslanger, S. and Witt, C., eds Adoption Matters. Ithaca, NY: Cornell University Press, 247-264.

Fogg-Davis, H., 2002. The ethics of transracial adoption. Ithaca, NY: Cornell University Press, 2002.

Folbre, N., 1994, Children as public goods. The American Economic Review 84 (2), 86-90

George, R., 1987, Who should bear the costs of children? Public Affairs Quarterly, 1 (1), 1-42

Hannan, S., and Vernon, R., 2008, Parental rights: a role-based approach. Theory and Research in Education 6 (2), 173-189.

Gheaus, A., 2012, The right to keep one's biological baby. Journal of Political Philosophy, 20 (4), $432-455$

Gheaus, A., forthcoming. What abolishing the family would not do. Critical Review of International Social and Political Philosophy.

Goodin, R., 1985. Protecting the vulnerable: a re-analysis of our social responsibilities. Chicago: University of Chicago Press.

Liao, S.M., 2015. The Right to be Loved. New York: Oxford University Press, 2015.

Macleod, C., "Parental Competency and the Right to Parent", in Hannan, Brennan and Vernon (eds) Permissible Progeny: the morality of procreation and parenting, Oxford University Press, 2015, pp. 227-245.

MacLeod, C., 1997. Conceptions of parental autonomy. Politics \& Society, 25 (1), 117-140.

McTernan, E. 2015. Should fertility treatment be state funded? Journal of Applied Philosophy, 32 (3), 227-240.

Olsaretti, S., 2013. Children as public goods? Philosophy and public affairs, 41 (3), 226-258.

Schoeman, F., 1980. Rights of children, rights of parents and the moral basis of the family. Ethics, $91(1), 6-19$.

Shields, L., 2016. How bad can a good enough parent be? Canadian journal of philosophy, 46 (2), 163-182.

Tomlin, P., 2015. Should kids pay their own way? Political Studies, 63 (3), 663-678.

Vallentyne, P., 2003. The rights and duties of childrearing. William and mary bill of rights journal, 11 (3), 991-1009. 